\title{
BRIGHTNESS, WELL-BEING AND WORK
}

\author{
BY
}

\author{
H. C. WESTON *
}

London

\section{Introduction}

Seeing is a function of lighting and, since the former is immensely important for the well-being of man in general, the latter necessarily demands inclusion among the basic requisites for health, with which social, and thus industrial, medicine must concern itself.

It is true that seeing is possible in widely different conditions of lighting, but it is this very fact that leads to much abuse of the eyes, and neglect to consider and secure those conditions which are necessary for visual efficiency, as well as for general comfort and health.

There has, however, been considerable improvement in the artificial lighting of many factories during the thirty years which have elapsed since the first appointment of a departmental committee to consider the lighting of factories. During the period of the present war much has been done to bring the artificial lighting in vital factories up to desirable standards, though it is unfortunate that, at the same time, admission to them of natural daylight has been restricted, and often avoided altogether. But there is still much unsatisfactory lighting in industry, particularly, though not exclusively, in the smaller factories.

It was not until the advent of the Factories Act of 1937 that there was included among the general statutory provisions for safeguarding health one requiring sufficient and suitable lighting, whether natural or artificial, in every part of a factory in which persons are working or passing. Nearly four years later, the Factories (Standards of Lighting) Regulations, 1941, were made under Section 5 of the Act. These define some of the conditions which, for the time being, are accepted as ' sufficient and suitable,' though the regulations are, at present, applicable only to factories working more than 48 hours a week, or in shifts. There are no similar regulations enforceable in offices and other places of employment.

The distinction between sufficiency and suitability is conventional, and in some respects convenient, but, clearly, no lighting can be entirely suitable for any given purpose unless it is also sufficient. What is meant by the expression 'sufficient lighting' is merely the amount of light, or the illumination, which ought to be provided on the work so that it can be done without straining the eyes, and the amount of light which ought to be provided else-

* Investigator to the Industrial Health Research Board. where in the factory for convenience and safety in passage about the premises. On the other hand, the expression 'suitable lighting' is used to cover a number of factors-some quantitative and some qualitative - such as diffusion and direction of the light, the placing and screening of light sources to avoid troublesome shadows and glare, and the spectral composition of the light. But, of course, sufficiency and suitability, as thus defined, are both essential for good lighting, and quantitative standards of illumination, when specified, are only valid when other conditions of lighting are suitably arranged.

\section{Brightness and Illumination}

The object of all lighting is to give brightness to external objects, whereby they become visual stimuli capable of exciting a sensation to which the term brightness is also applied. Physical, or stimulus, brightness is something which can be measured photometrically. Objects have this brightness either because they emit light directly, as in the case of electric lamps, or because they reflect some of the light they receive from the light sources illuminating them. It is usual to express brightness in candles per square inch, the candle being the unit of luminous intensity. The current Factory Lighting Regulations restrict the permissible brightness of any part of a light source or lighting fitting which is visible to persons employed within 100 feet of it to ten candles per square inch, unless the source is mounted more than 16 feet above the floor, or the angle of elevation from the eye to the source exceeds 20 degrees. This brightness is appreciably greater than the average brightness of the day sky.

The brightness of a surface which reflects light depends on the nature of the surface, the illumination it receives, and the angle from which it is viewed. Polished surfaces, which reflect light regularly, may have a brightness in a particular direction almost equal to that of the sources illuminating them. Matt surfaces reflect light diffusely and may present almost the same brightness in any direction of view. Brightness, in this case, is proportional to the product of the illumination of the surface and its reflection factor, the latter being simply the ratio of the light flux the surface reflects to that which it receives. The reflection factor depends on the colour of the surface, and also on the "colour' (wave length composition) of the light illuminating it. It is quite common to express the brightness of diffusely reflecting surfaces in equivalent footcandles or, synonomously and preferably, foot- 
lamberts. (These units are converted to candles per square inch when divided by $452 \cdot 4$ ). The term 'equivalent foot-candle' is derived from the unit of illumination which, in Britain and America, is the foot-candle, and, since brightness depends on illumination and reflection factor, it is not surprising that a term based on the foot-candle should have come into use for expressing brightness values, though photometrists prefer the alternative 'footlambert.'

The foot-candle itself is the illumination a surface has when it receives unit quantity of light flux per square foot. And, as the unit of light flux is called the lumen, it follows that an illumination of one footcandle is equivalent to one lumen per square foot. If a given light source, such as an electric lamp, emits a thousand lumens (units of luminous flux) and, with the aid of a suitably designed reflector, 70 per cent. of this flux be uniformly distributed over a surface one square foot in area, the surface is given an illumination of 700 foot-candles, or lumens per square foot. If the surface is white, having a reflection factor of 0.8 , its brightness is then $700 \times 0.8=560$ equivalent foot-candles; but if the surface is very dark in colour, having a reflection factor of 0.06 , its brightness is only 42 equivalent foot-candles. As it is only the brightness, and not the illumination, which the eye appreciates, it will readily be understood that the reflection factor of the objects we wish to see has a most important bearing on the illumination that must be provided.

Illumination can be measured, with sufficient accuracy for factory purposes, by means of a simple photo-electric photometer giving a direct reading of the foot-candle value at any point where the instrument is placed. In measuring the illumination on the work which is being done in a factory, office, or elsewhere, it is, of course, essential to place the light-sensitive plate of the photometer in the position normally occupied by whatever the worker has to see, and the measurement should be made with the worker in his usual position so that the instrument takes into account the effect of any shadow he may cast on the work. Instruments of this type are affected by the colour of the light used. They are usually calibrated for the light given by tungsten filament lamps, and correction factors are given by the makers to be applied to readings taken in light of different colour quality. The correction for daylight is small, and can usually be neglected.

It will be understood, from what has been said above, that measurement of the illumination available does not, of itself, indicate whether or not the lighting is adequate for its purpose. Such measurements must be considered in relation to the nature of the illuminated objects, and the dependence of the eye to see them upon the brightness stimuli it receives. As already explained, a high illumination may mean only a low brightness if the work illuminated has a low reflection factor. The brightness of the work cannot be measured so simply as its illumination, but can be derived approximately from the latter if the reflection factor of the work is estimated by matching it with one of a series of samples whose reflection factors are known.

In the case of daylight, the illumination anywhere inside a building can, of course, be measured with a portable photometer as described above. Daylight illumination varies, however, over a wide range during the course of each day, and also with the seasons. It would, therefore, be necessary to make a large number of measurements at different times of the day and year in order to obtain an average value for the daylight illumination at any particular point. This difficulty is avoided by measuring the daylight factor at the points of principal interest, e.g. individual work places. The daylight factor is simply the fraction (usually expressed as a percentage) of the illumination available outdoors, from the whole hemisphere of sky, which reaches the point under consideration inside a building. It is determined by measuring, simultaneously, the illumination at the chosen point in the building and that outside at a point exposed to the diffuse light from the whole sky. Thus two observers are required. It is a convention, in this country, to assume an outdoor illumination of not less than 500 foot-candles for the purpose of deciding what will be a satisfactory daylight factor in any given case, i.e. what factor will ensure adequate interior illumination during a reasonable proportion of the annual hours of daylight. On this basis, it is evident that any point having a daylight factor say of 1 per cent. will usually have an illumination of not less than 5 foot-candles. This value will be exceeded whenever the outdoor illumination is more than 500 foot-candles, and at times, particularly in the summer months, the interior illumination at such a point will reach 25 or 30 foot-candles.

\section{Factors Affecting the Amount of Light Required}

Although, strictly, adequacy cannot be abstracted from suitability as an aspect of lighting, it will be convenient to treat it as separable, with the proviso made in the introduction. Accordingly, we shall deal first with the question, how much light is necessary for the eyes to meet the demands made of them in industry?

Any particular kind of work can be seen under widely different amounts of illumination, though it cannot be seen with the same ease, certainty, and speed over the whole effective range. Small needles can be threaded all day in the light of a candle giving only a few units of illumination-providing we do not mind how slowly the work is done, how much effort is wasted in unsuccessful attempts, how much the eyes ache and burn at the end of the working day, or how irritable we become, and how disinclined, or unable, we are to use the eyes for such leisure pursuits as reading. The same task can be done near a window in daylight, but with very different results. Here there may well be more than a hundred units of illumination available on the work. If it were done out-of-doors this illumination might be multiplied tenfold, and this would not be harmful, though it might be more than is really needed to do the work as well as possible, and with the least fatigue.

For every task in industry for which the eyes are used there is a minimum illumination, with which visual perception of the work is only just possible, and an optimum illumination, beyond which no apparent advantage may be gained. Between these extremes the gap is wide, and for some industrial operations the real optimum is never reached indoors, even in daylight. It is only the optimum illumination with which management and preventive medicine ought to be concerned, and to make the question posed above more explicit it must be asked -how much light is required to promote good 
health, comfort, and safety, and thus to be consistent with the maintenance of a high standard of industrial efficiency? The answer involves the consideration of a number of factors, some physical, some physiological, and some psychological.

\section{(a) Analysis of the Visual Task}

In the first place, the physical characteristics of the objects of vision are involved, in so far as they affect the amount and quality of the light passed on, or reflected, to the eyes when the objects are illuminated. All objects absorb some of the light they receive and reflect the rest, either diffusely in all directions, or regularly in a direction depending on that from which the incident light comes. Hence, of course, white and black objects, which reflect very different fractions of the light they receive, must have very different illuminations to give them equal brightness, as already explained in section II. Also, there must be a difference of brightness, or colour, or of both, if an object is to be distinguished from others adjoining it and forming its ' setting.' This difference, or contrast, may have to be accentuated, or created, by providing different amounts of light on adjacent objects or parts of an object which, owing to their similar properties of reflection, would not otherwise be discriminated.

The physical dimensions, and distance from the eyes, of the work objects are of great importance in relation to the amount of illumination required, since these determine the size of the retinal image and the acuity of vision called for. Another physical variable, in some industrial tasks, is motion, and this affects the illumination required if details of the moving objects need to be clearly discerned.

These are characteristics of the work which can be measured, though not always easily, nor with great precision. As yet, there has been no systematic attempt to do this as carefully as it might be done, and so to obtain the most exact data from which to deduce the visual capacity required, and the necessary conditions of lighting. 'Diagnosis,' of the task is clearly the necessary preliminary to the prescription of a proper dose of illumination. Also-as in medical practice-the diagnosis will be more precise and reliable the more completely the physical ' signs' are observed and subjected, as far as possible, to actual measurement.

In making this diagnosis, or assessment, of the task, it is important to remember that the 'critical' detail that has to be seen is not always a permanent feature of the work-objects. It may exist only momentarily, being created in the course of the action of the worker upon his materials-as in assembly, when two parts are being brought into connection. The familiar task of threading a needle, already mentioned, is a case in point. Here it is not the size of the eye of the needle which is the smallest detail to be seen, but that part which is seen when the thread is so positioned that penetration can be successfully accomplished. Similarly, in assembling the pivots of the moving coil for small electrical measuring instruments, it is not the complete hole into which the pivot has to be inserted which determines the fineness of visual discrimination required. It is the size of that fragment of the hole by which the worker sees that the final act of pushing home the pivot can be proceeded with, without risk of missing the goal and damaging the adjacent delicate wire On the other hand, in some inspection processes, a fixed feature of the objects scrutinized constitutes the critical detail, and there should be no difficulty in measuring its size and the contrast it presents with its immediate surrounds. The analysis of tasks to determine the operations involved is already widely practised in the pursuit of industrial efficiency, and their analysis and measurement for the purpose of setting standards of vision and lighting is no less necessary.

\section{(b) Effects of Variation of Illumination}

(i) Noticeable Differences.-In the case of sight, as of the other special senses, the least noticeable difference of stimulus is a function of the stimulus itself, i.e. it is not a constant quantity but a constant fraction of the stimulus intensity. This is broadly true within limits of intensity which cover the range of illumination levels necessary in factories, as will be seen from Fig. 1.

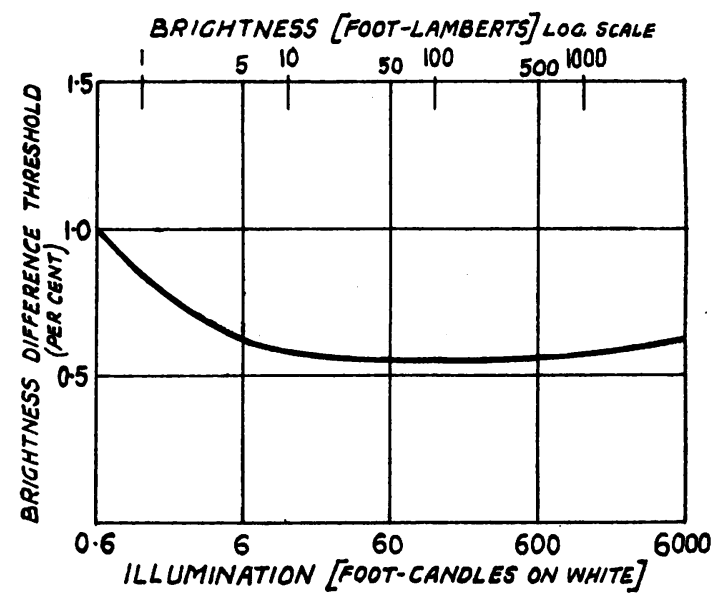

FIG. 1.- Intensity discrimination curve.

Within these limits, we do not appreciate the difference between two lights unless the intensity of one differs from the other by at least a certain percentage, which does not vary and determines the size of the smallest discrimination step. It is the ratio of the two intensities, and not the arithmetic difference between them, upon. which our experience of their unlikeness depends. Hence, successive equal increments of illumination become progressively less effective and, eventually, become relatively too small to make any appreciable difference. This is readily illustrated by switching on the artificial light in a room at twilight and again in broad daylight. In the first case, a very distinct improvement in the illumination is noticed, but in the second, the same additional amount of light-being only a small instead of a large fraction of that already present-makes little or no noticeable difference.

Thus, if we have the problem of effecting a similarly noticeable improvement in the brightness of two rooms, one of which already has a low and the other a high illumination, the same proportional increase in the existing illumination should be made in each case. The result will not be achieved by the addition of the same number of foot-candles to the illumination in each room. This principle is of fundamental importance in lighting practice.

(ii) Visual Acuity.-It is brought out again when 
we consider the relation between illumination and visual acuity. Lythgoe (1932) has shown that visual acuity is proportional to the logarithm of the brightness, or corresponding illumination, of the object, and that it improves up to a level of illumination exceeding 1200 foot-candles, providing the surroundings are also adequately illuminated. Thus, successive equal proportional increments of illumination are necessary to produce equal arithmetic increments of visual acuity, and so to enable correspondingly smaller detail to be seen. Fig. 2 shows the relation found by Lythgoe.

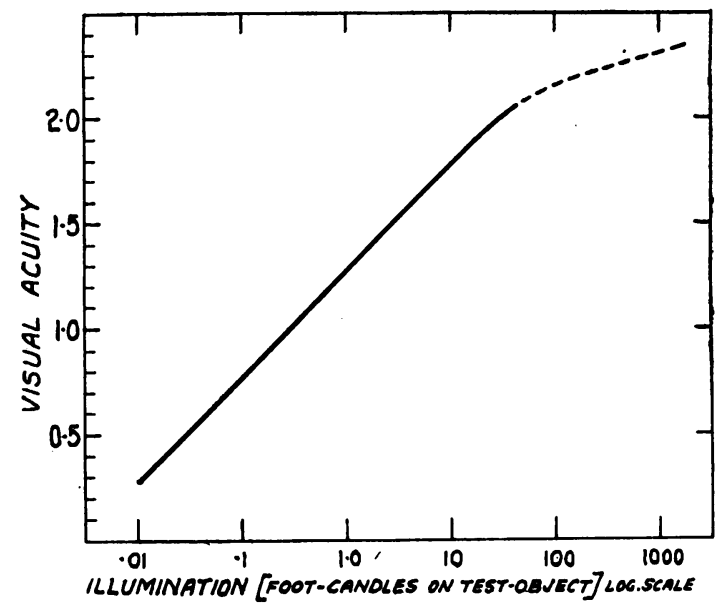

FIG. 2.-Variation of visual acuity with illumination (Lythgoe).

Visual acuity is expressed as the reciprocal of the angle visually separable, and the minimum acuity required for any industrial task can be found if the dimensions of the detail that must be seen and the distance of the objects from the eyes are measured. The minimum illumination necessary could then be derived from Lythgoe's relation, but is of no interest as a practical standard, being merely sufficient to give a slightly better chance of seeing than of not seeing the critical detail. What is really required is sufficient illumination for rapid, certain vision, and it is, therefore, necessary to know how visual performance improves when illumination is raised above the liminal value.

(iii) Illumination and Size of Detail.-Investigation of the variation of visual performance when illumination is thus increased has shown that the minimum illumination for a task presenting a given size of detail must be very greatly exceeded in order to obtain the greatest ease and speed of seeing. This is shown by the curves of Fig. 3, which are plotted from data obtained by Weston (1935). The task studied involved continuous visual inspection, and presented detail ranging in visual size from 1 to 10 minutes, i.e. demanding a minimum acuity ranging from $1,(V=6 / 6)$, to $0 \cdot 1,(V=6 / 60)$. It will be seen, for example, that the task requiring at least so-called ' normal' acuity $(\mathrm{V}=6 / 6)$ can only be done with maximum efficiency if the illumination is more than a thousand times the value with which this acuity is just possible.

From Fig. 3 it is also seen that as the fineness of the work increases (i.e. size of detail decreases), the illumination required to maintain the same level of relative performance increases in much greater ratio.

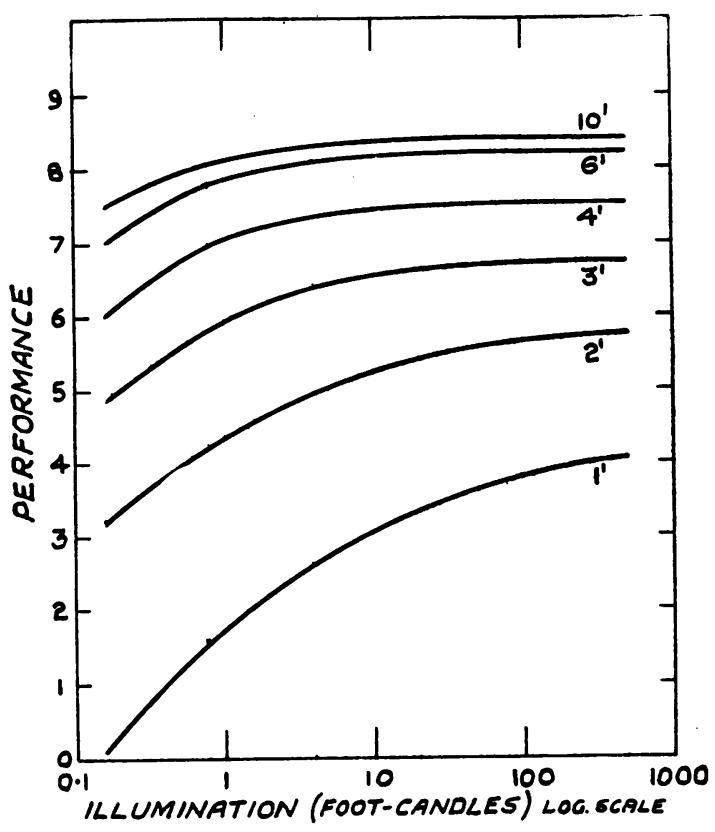

FIG. 3.-Variation of performance with illumination and size of detail requiring discrimination. Size is given in minutes of arc subtended at the eye by critical detail of the object. From this family of curves values of illumination can be found such that relative efficiency in performing tasks differing in size, between the limits shown, is independent of size.

Considerable changes of illumination are needed to bring about small changes of acuity. It follows that if the size of detail that has to be seen in any practical visual task can be varied, a given enlargement is much more effective in easing the task than

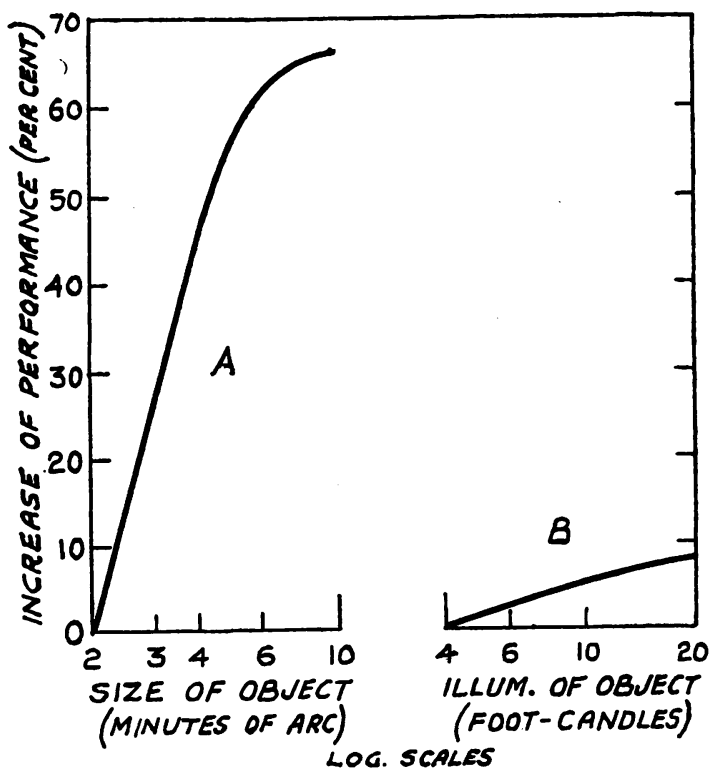

FIG. 4.-A shows the effect of magnifying size 5-fold (from 2 to 10 mins.) illumination being constant at 4 foot-candles. B shows the effect of magnifying illumination 5-fold (from 4 to 20 foot-candles), size being constant at 2 minutes. 
is a similar proportional increase of its illumination. This is clearly shown by Fig. 4.

Usually the physical size of the objects to be seen is fixed, but the apparent size of these can be varied by varying their distance from the eyes. This, of course, is what is done when illumination is inadequate. By bringing the eyes nearer to the work its apparent size is increased until it is brought within the restricted visual capacity. The near point limits the extent of the enlargement obtainable in this way, and, as a method of compensating for lack of light, shortening the viewing distance is frequently responsible for the development of accommodative asthenopia, and for fatigue due to the posture the worker may have to adopt.

However, it is not generally realized how much the illumination may have to be improved to avoid viewing the work so closely that accommodation and convergence of the eyes is greater than can be sustained with comfort. Suppose, for example, a person engaged on fine work - say fuse assemblyfinds it necessary, with the prevailing illumination, to view the work at a distance of only nine inches. As ten inches is usually regarded as about the shortest comfortable distance of the eyes from the work, how much must the illumination be increased to maintain the visibility of the work while giving the worker the benefit of the additional inch? Now if the viewing distance is thus increased in the ratio $10 / 9$, the apparent size of the detail that has to be seen will be reduced in the ratio $9 / 10$, i.e. it will be 10 per cent. smaller. It has been shown elsewhere (Weston, 1943) that this necessitates an increase of illumination of about 40 per cent. If the working distance were lengthened to eleven inches the apparent size of the detail would be reduced by about 18 per cent., and the illumination would need to be nearly doubled. These conclusions are in accord with practical experience, and receive support from the earlier work of Lythgoe (1932) already referred to. To obtain the higher illumination required to lengthen the working distance by one inch might mean, e.g. replacing a 60 -watt lamp by one of 75 watts (giving about 30 per cent. more light) and placing it a little nearer the work. Alternatively, the distance of the 60-watt lamp from the work might be reduced by 15 per cent. To lengthen the working distance by two inches the size of the lamp would have to be increased from 60 to 100 watts, or the 60 -watt lamp be placed 30 per cent. nearer the work.

(iv) Illumination and Contrast in Task.-The differentiation of objects within the field of vision depends essentially upon the contrast of brightness or colour between them. A particular contrast of light and shade, or its equivalent when the contrast is that of black print on white paper, or a grey pattern on a different grey ground, is completely defined in physical terms by the two objective brightness values involved. It is, however, the ratio and not the difference of these values which determines the degree of contrast, i.e. whether it is 'strong' or 'weak,' ' high' or 'low,' in the scale of physical brightness contrasts. And it is also the ratio of the contrasting stimulus brightnesses which chiefly determines the sensation of difference, or contrast, experienced, and the relative 'goodness' of different contrasts as appreciated by the eye. Thus, the contrast between two high brightnesses, whose ratio is low, is a poor one as compared with that between two much lower brightnesses whose ratio is high, even though the arithmetic difference between the first pair is larger than that between the second pair. For example, the contrast between two slightly different shades of grey paper is poor compared with that between pieces of black and white paper, and remains so even if the greys are highly and the black and white poorly illuminated, i.e. even if the difference of brightness presented by the greys is made greater than the difference between the black and white.

The degree of brightness contrast presented by such surfaces, or by self-coloured but textured surfaces, can, however, be modified by the conditions of lighting. These may be arranged to provide a selective distribution of light, or to take advantage of the properties of reflection of particular objects so as to enhance or diminish their brightness in the usual direction of view.

Subjectively, however, degree of contrast does depend partly on the difference as well as the ratio of the brightness stimuli involved. Thus, if a grey pattern on a slightly lighter or darker grey ground is suitably illuminated the pattern can be seen, although the contrast between it and its background may be very poor. If the illumination is gradully reduced a point is reached when the pattern disappears. In this case the brightness ratio of pattern and ground is not altered. But the difference of brightness between pattern and ground is reduced in the same proportion as the illumination, and becomes smaller than the eye can detect.

Above a certain level of brightness, or illumination, the contrast sensitivity of the eye does not continue to improve, i.e. the poorest contrast that can be appreciated requires that the brightnesses involved shall bear to each other a minimum ratio which is constant, whether the actual brightness values are near to or considerably above the level at which maximum sensitivity is reached. This can be seen from Fig. 1 .

But the speed and thus, presumably, the ease with which all supra-liminal contrasts are perceived improves as the brightness of the two components of the contrasts, and therefore their difference of brightness, is raised to a much higher level. This is true for contrasts as encountered in the majority of common visual tasks where the recognition of detail is involved. Fig. 5 illustrates this effect, each curve showing the relation between illumination and the performance of a simple visual task involving perception of detail of constant size but different degree of contrast.

The poorer the contrast the lower the performance. But, whatever the contrast, performance improves with illumination and this improvement is relatively greater for poor than for good contrasts. Thus, a pencilled note on white paper is less easy to read than a similar ink-written note when both are seen under the same illumination-say 3 foot-candles. The visibility of the pencilled script, relative to that of the ink script, will be improved if both are seen under higher illumination-say 30 foot-candles; and the respective visibilities will differ still less if the ink note is illuminated to 3 foot-candles while the pencilled note is given 30 foot-candles.

It was suggested by Beuttell (1934) that the best method of compensating for inferiority of contrast might be to adjust illumination in such a way that the difference of brightness between the contrasting 


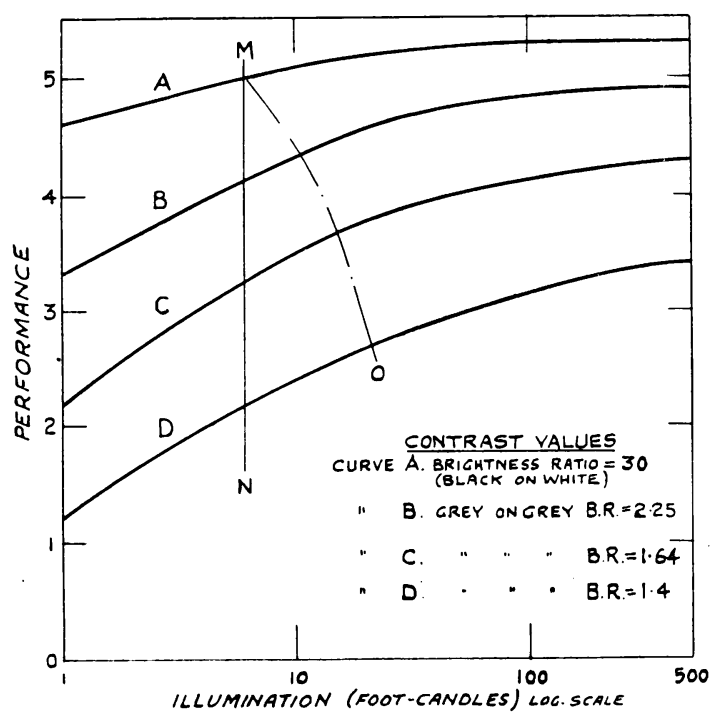

FIG. 5.-Variation of performance of a visual task with contrast and illumination. The line $\mathbf{M}-\mathbf{N}$ is drawn at $6 \mathrm{ft}$./cs., and its intersection with each curve indicates the performance obtained at this illumination with each contrast. The curved line $\mathrm{M}-\mathrm{O}$ intersects each curve at a point corresponding with the illumination at which that contrast will present the same brightness difference as the best contrast does at $6 \mathrm{ft}$./cs. The change in performance should be noted. Size of detail in the object was $3 \mathrm{~min}$. in each case.

elements which reveal the important detail in a visual task would have the same value for all degrees of contrast. This value would be that found to give satisfactory visibility of detail of the given size when the contrast by which it is seen is the best possible, (Theoretically, perfect black-reflection factor $=0$, and perfect white-reflection factor $=1.0$ ).

From an experimental study of the variation of visual performance with contrast and illumination, Weston (not yet published) found that when the illumination of visual tasks involving different degrees of contrast is so chosen that the brightness difference presented in each contrast is the same (i.e. is independent of the degree of contrast) the visibility of the different tasks still varies directly with the contrast, though their relative visibilities are less disparate than under conditions of illumination such that poor contrasts present a lower brightness difference than good contrasts. Nevertheless, subject to certain limitations, Beuttell's rule for 'correcting' illumination according to the contrast presented in the visual tasks is a useful one.

If, however, the contrast by which the detail of objects is revealed can be improved by modifying the material objects themselves, a change in this respect may be a much more effective aid to vision than a similar relative change of illumination. Such modification is often possible in practical industrial tasks. The immediate background of objects to be inspected, and the materials of which the objects are made, or at any rate their surface colour and finish, are often open to choice, and it is sometimes only tradition and habit which prevents the exercise of this choice in favour of good visibility.

Fig. 6 deals with a simple case, and shows that if the ratio of paper and print reflection factors (a measure of contrast) in a visual discrimination test is multiplied, say tenfold, by substituting black print on white paper for grey print on a slightly different grey paper, the speed and accuracy of visual discrimination is greatly improved without any increase of illumination. If, however, the poorly

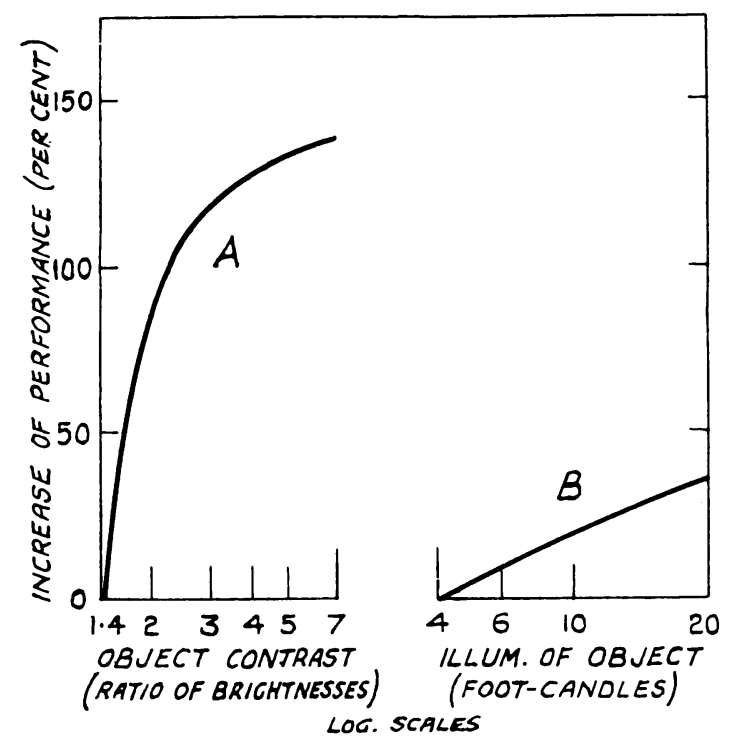

Fig. 6.-A shows the effect of magnifying contrast 5-fold (from B.R. $=1.4$ to $B . R .=7$ ), illumination being constant at 4 foot-candles, and size constant at 3 mins. B shows the effect of magnifying illumination 5 -fold (from 4 to $20 \mathrm{ft}$./cs.), contrast being constant at B.R. $=1 \cdot 4$, and size constant at 3 mins.

contrasting greys are retained, but their illumination is multiplied tenfold, the resulting improvement of performance is relatively small.

Hence, whenever the materials and dimensions of the work objects are not imposed upon the designer or manufacturer by more important considerations, they should be chosen with due regard to the severity of the visual task they will create for the worker, and the illumination this will demand. As ' a stitch in time saves nine,' so a small enlargement of size or contrast, when this is feasible, may save a lot of light-and eyestrain.

(v) Illumination and Industrial Performance.-A number of investigations have been made, in this and other countries, to determine the relation between illumination and the performance of workers in different industries. The effect of variation of illumination upon output has also been observed incidentally in the course of factory studies primarily concerned with other environmental factors. In general, it can be said that the results of most of these studies show the need for higher values of illumination than those current when the investigations were made. In some cases they suggest the optimum illumination for processes of certain classes, using quantity and quality of output as the criteria.

Thus, Elton (1920) showed that the output of silk weavers during the first two months of the year rises steadily as the daylight illumination increases, and the duration of artificial lighting decreases. From data relating to the variation of daylight during this period, it can be inferred that the optimum illumina- 
tion for the work considered is not less than about 30 foot-candles. Weston (1922) showed the effect of inadequate daylight, and also artificial light, on the output of linen weavers, and Wyatt (1923) observed an increase of about 5 per cent. in the efficiency of cotton weavers when adequate daylight was available instead of the low illumination (little more than $1 \mathrm{ft} . / \mathrm{c}$.) available by artificial light. Weston (1938) also studied the effect on output of varying the illumination provided for worsted

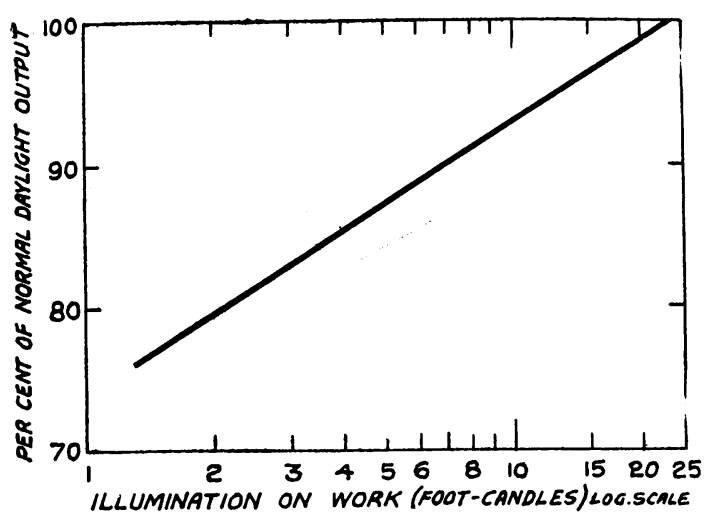

FIG. 7.-Variation of output with illumination in typesetting by hand.

weavers, working entirely by artificial light, and concluded that the optimum value on the cloth (medium coloured suitings) is of the order of 30 $\mathrm{ft}$./cs. With this illumination the personal efficiency of the weavers, as distinguished from the weaving efficiency measured in terms of machine running time, was 24 per cent. better than with rather less than half the amount of light.

The effect of illumination on the quantity and quality of output, in a fairly fine industrial process,

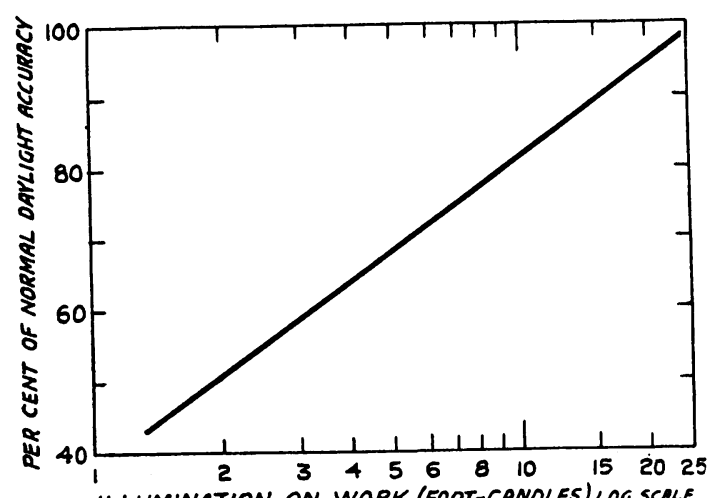

FIG. 8-Variation of accuracy with illumination in typesetting by hand.

is very clearly shown in the results of a study of typesetting, made by Weston and Taylor. These results are represented in Figs. 7 and 8.

It can be seen from Fig. 7, that, within the limits of illumination considered, the relation between amount of work done and the illumination provided is of the same kind as the relation which holds between visual acuity and illumination, i.e. the work done increases by equal increments for equal proportional increments of illumination. At about $24 \mathrm{ft}$./cs. the output of work is equal to that done in good daylight. Fig. 8 shows that the proportion of mistakes in the work done decreases as the illumination increases, and here again the daylight norm is reached at $24 \mathrm{ft}$./cs.

Though it has not been possible to make strictly valid comparisons between output before and after the improvements in illumination which have been effected in many factories during the war, some managements have been able to make rough assessments of the gain probably due to better lighting. Of those known to the author, most are reasonably consistent with expectation based on pre-war investigations dealing with changes of illumination of similar magnitude.

(vi) The Effect of Movement.-It is well known that if a clear image of moving objects is to be obtained, the illumination must be better than it need be for seeing stationary objects. And, for any given rate of movement the illumination required will depend upon the factors already considered, namely, size, and contrast. As the rate of movement increases, the time during which the stimulus provided by the object acts upon any retinal receptor decreases. Thus the response of the receptors must be speeded up, otherwise the effect of one stimulus will not be fully developed before another is applied, thus causing the visual images to be blurred. Flicker experiments show that the response of the cones is speeded up, i.e. their reaction time is reduced, as illumination is increased but, of course, however high the illumination is made there is a minimum below which this reaction time cannot be reduced. It is difficult to express this in terms of rate of movement of objects which have to be discriminated in motion during factory processes. The matter is complicated by the fact that the eyes can often follow the moving object, and so keep its image nearly stationary on the retina. When this is not possible flicker experiments suggest that, within limits, as the rate of movement is increased arithmetically the illumination must be increased geometrically. However, the effect on the illumination required, due to relative movement between eye and object, has not yet been adequately studied under practical conditions. At present, therefore, the illumination for processes involving discrimination of moving objects must be determined on the basis of their static characteristics, with an arbitrary allowance for movement, or must be found empirically in each case.

\section{(c) Psychological Considerations}

Bad lighting is necessarily an obstruction to normal visual activity and, for this reason, occasions disagreeable feeling. This varies in intensity and distinctness according to the extent and nature of the unwanted restriction imposed on visual experience, and it may be modified by recognition of justifying, or extenuating, circumstances for this restriction. It is, however, augmented and heightened by the feeling of strain aroused by organic sensations accompanying ocular adjustments which are made in more or less ineffectual efforts to overcome the impediment. In the extreme case-as described in one of Poe's tales *-the feeling is of ' eyes straining from their sockets.'

* The Pit and the Pendulum. 
There is no doubt that the disagreeable feeling thus aroused by strain in seeing, and the imperfection and limitation of the visual impressions received, affects the higher emotional life. It is quite sufficient to induce annoyance and bad temper or depression, which, if prolonged, or frequently experienced, passes into a settled mood through which the general outlook is distorted. The mental soil is then well prepared for any other seeds of discontent to germinate and flourish with weed-like proliferation. Moreover, this state of mind is easily carried over into extra-industrial life, and in this way the 'sins' of the factory may be visited upon the family, or have still more remote undesirable consequences. Of course, this is equally true whatever factory condition, or conditions, may be the exciting cause, but this in no way lessens the potency of lighting in this respect.

One of the effects noted during the war in blackedout factories, where artificial light has been very unevenly distributed, and substantial areas of semidarkness intervene between workplaces, is the sense of isolation which workers tend to experience. They feel almost cut off by gloom from visual intercourse with their fellows, and with their surroundings, so that the team spirit and the corporate life of the group tends to be weakened, and the social urge thwarted.

Even, however, when there is no noticeable sense of strain in seeing either the work itself, or the contents of the wider visual field which are of general interest, lighting may have little or no positive psychological value. It is, of course, well known that excitation of the senses is pleasurable up to a certain point and, until this point is reached, the degree of pleasure increases with the strength of the stimulus. The sense of sight affords no exception to this rule, and the pleasure accruing from visual stimulation is enhanced by values of the stimulus which may much exceed those which suffice for satisfactory visual scrutiny of the workobjects themselves, when these involve no small detail. The most familiar demonstration of this truth lies in the universal experience of apparent enhancement of the vis vitae experienced on clear bright days, for which there are many colloquial expressions-such as 'feeling on the top of the world - and the feeling of subnormal vitality on days that are cloudy and relatively dull. The illumination on both occasions may be adequate for easy seeing, but the superior pleasure of the former is undeniable. "Truly the light is sweet, and a pleasant thing it is for the eyes to behold the sun.' These epigrammatic words from Ecclesiastes express a profound truth, of which too little account is taken in much industrial lighting practice. And the degree of vitality and pleasure we feel on bright days does not result merely from that satisfaction of our sense of congruity given by knowing that the sun is not masked, but is due, at least in part to the intensification of visual excitation by the higher prevailing brightness.

Thus, providing there is no glare (vide infra), psychological considerations suggest that, when engaged in industrial activity, and irrespective of our specific needs for the particular task involved, the more light we have the better we like it. And this is true up to a level of several hundred foot-candles, such as may be had near a large window for some hours on an average bright day.
That the variation of feeling associated with sensory stimulation may be correlated with muscular activity is well known, and a general statement of this relation is to be found in any account of the psychology of feeling. Wundt puts it succinctly' a feeling of joy and excitation makes movement easy and prompt; a depressing feeling renders it slow and heavy.' * While personal experience has doubtless convinced us all of this-so that to state it explicitly is perhaps to be trite-its importance in connection with lighting is often unappreciated, judging from many examples of current industrial practice. Experimental evidence of the motor response to light stimulation is available, however, and Fig. 9 shows that rate of movement may con-

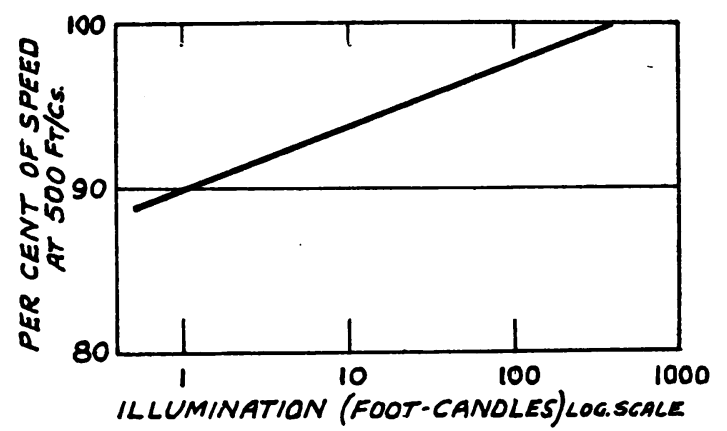

FIG. 9.-Illumination and rate of working in an easy visually guided hand operation.

tinuously improve as illumination is raised up to the level suggested above.

This graph refers to a group of subjects performing a simple cancellation test in which the objects to be marked were large enough for the speed of visual recognition to be nearly independent of illumination, over the range shown, so that the slope of the curve is chiefly due to variation of the rate of arm and hand movement. This effect appears to vary-as does the acuity of the eye-with the logarithm of the illumination, i.e. it grows by equal steps when the stimulus follows the "law of organic growth.' But, since it is evident that the change in rate of activity is small compared with the variation of illumination required to produce it, values of illumination of a much lower order than the psychologically optimal can be used without serious detriment. This is fortunate, because the reproduction of daylight intensities in general lighting by artificial sources would be costly, and not always easy to achieve without glare and undue heat. Moreover, though there is no evidence that such intensities are not just as pleasurable with artificial as with natural light, providing other important characteristics of the lighting are equally satisfactory, we do not demand such high values of illumination, when daylight is not expected, in order to satisfy our sense of congruity.

Nevertheless, the minimum level of illumination required to maintain a psychologically satisfactory brightness environment exceeds the average value provided by artificial. light in many factories even to-day.

Failure to provide this minimum occurs most frequently in factories, or parts of factories, where the tasks performed obviously do not require high

\footnotetext{
* Wundt, W., Human and Animal Psychology.
} 
degrees of visual capacity. In such cases the work may be seen well enough with a low level of illumination, which is not infrequently provided by local lights at actual workplaces, leaving the general environment to be illuminated by stray and reflected light. This is the result of a superficial view of the purpose of factory lighting, whereby it is considered to have only one essential function-namely that of illuminating the work.

It is, of course, only with reference to the average factory that it is possible to suggest a single value of illumination as the psychological, or 'amenity,' minimum. Since it is brightness with which we are really concerned, it is clear that this average value will be too low for factory interiors which are abnormally dirty, or have their structural surfaces, fixtures and plant painted in dark colours. Conversely, though it will not be too high for unusually clean factories with light-coloured decorations, it may be somewhat reduced if economy in lighting is a serious need.

The actual value of this minimum for.the average factory can be put at about $6 \mathrm{ft}$./cs. With this value it will be seen on reference to Fig. 9 that the rate of working of the group studied is about 93 per cent. of the rate recorded at the highest illumination used, viz. $-500 \mathrm{ft}$./cs. It seems reasonable to expect that lighting shall be good enough to permit a standard of efficiency of this order. But Fig. 9 is based on tests made in a laboratory having light decorations, though the conclusion reached is supported by the results of observations by Adams (1935) -made over a much longer period of time-of the output of persons engaged on rough work (tilepressing) -in a factory. Fig. 10 gives a smoothed

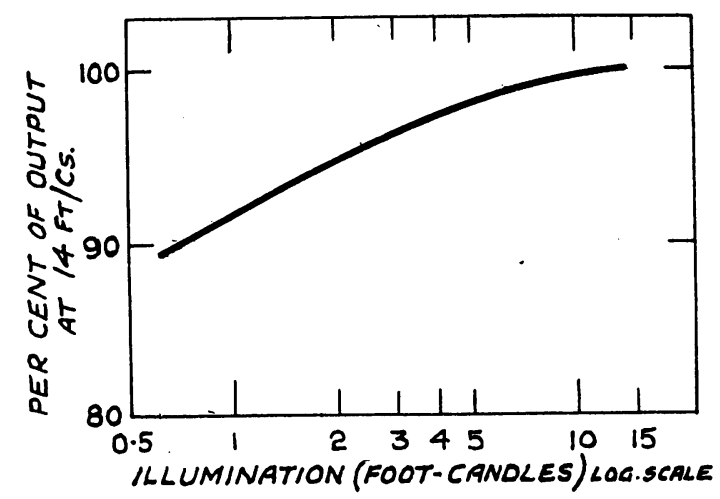

FIG. 10.-Variation of output with illumination in rough work (tile-pressing).

curve showing the relation between the output of the workers and the illumination used. The lowest illumination, $0.6 \mathrm{ft}$. $/ \mathrm{c}$., was that existing at the outset of the investigation, and this was stepped up at intervals of about six months until, finally, a value of $14 \mathrm{ft}$./cs. was used.

Though - to use a picturesque phrase of William James'- ' the trees don't grow into the sky,' $*$ it appears, from the curve, that the growth of output did not reach its ultimate limit with the highest illumination tried. Thus, although the output at $6 \mathrm{ft}$./cs. was about 98 per cent. of that at $14 \mathrm{ft}$. $/ \mathrm{cs}$. its relation to the possible maximum output is

* The Energies of Men. probably in closer agreement with the figure obtained from Fig. 9.

From consideration of the available evidence, and of demonstrations of the brightness produced by different illuminations under conditions found in factories, the Departmental Committee on Factory Lighting (1940) reached the conclusion that $6 \mathrm{ft} . / \mathrm{cs}$. should be recommended as the legal minimum illumination in working areas, at any rate in wartime when it is of vital importance that environmental conditions in factories should favour the maintenance of a high standard of health and efficiency. This value is specified in the Factories (Standards of Lighting) Regulations, 1941, made by the Minister of Labour, and is applicable (subject to certain exemptions) to all factories working 48 hours a week or more, or on shifts.

\section{Illumination Codes}

Scientific investigation of the illumination required has, so far, been limited to only a few of the great variety of industrial operations involving vision. The processes studied have, however, usually been selected as being apparently representative of many others, which can be classified as falling within one or other of a few broadly defined categories, e.g. rough, fine, very fine work. To the extent that results of actual investigations are available, they can be used as the basis upon which to found recommended orders of illumination for each such type of work. But, as stated earlier in this paper, there is, as yet, a lack of precise data, derived from analysis and measurement of particular industrial tasks, by which these may best be classified, or the illumination they require may be found synthetically from general relations existing between illumination and the principal factors involved in perception of the work. However, accumulated data relating to actual industrial lighting practice and, in particular, those obtained from organizations whose practice is dictated by the greatest concern for welfare and efficiency, afford an empirical basis for a scale of illumination levels applicable to the wide range of industrial processes. And these processes can be ranked or graded roughly-by persons of suitable experience-according to the difficulty of the visual task they present. The result is a catalogue of processes divided into sections, to each of which there corresponds an appropriate part of the illumination scale.

It is mainly on this basis that current illumination codes rest and, because they do so, they must necessarily be subject to revision from time to time, as fresh knowledge and experience leads to more accurate appraisal.

In this country, an illumination code is issued by the Illuminating Engineering Society (1942) and, in its current form, has set the standards adopted in the lighting of vital factories during the war. Its scale of values and classification of tasks is reproduced below.

It may be noted that the scale of values is not equally divided and, in fact, the means of the successive ranges form, approximately, a geometrical series. The need for this has, it is hoped, become apparent from the discussion in section III. Weston (1943) has proposed certain modifications of this code to establish it on a more fundamental basis, but these are concerned mainly with the regularization 
and extension of its scale, and the more precise grading of tasks.

\section{I.E.S. Recommended Values of Illumination for VARIOUS TASKS}

Foot-candles Class of Task

1. Above 50 Precision work to a high degree of accuracy; tasks requiring rapid discrimination.

2. $25 / 50$ Severe and prolonged visual tasks; discrimination or inspection of fine details of low contrast.

3. $15 / 25$ Prolonged critical visual tasks, such as proof reading, fine assembling, and fine machine work.

4. 10/15 Visual tasks such as medium machine and benchwork, and sustained reading.

5. 6/10 Less exacting visual tasks, such as casual reading and large assembly work.

6. $4 / 6$ Work of simple character not involving close attention to fine detail.

7. $2 / 4$ Casual observation where no specific work is performed.

While the I.E.S. code is not mandatory, attention is drawn to it in the 5th Report of the Departmental Committee on Factory Lighting as forming a valuable guide to the illuminations required for special classes of work. In Australia, a closely similar code has recently been adopted as the basis for legal minimum requirements in factories. In general, American recommended values of illumination are higher for all classes of work, and no value lower than 5 foot-candles is recommended. This scaling-up of recommended values means, of course, that a somewhat higher standard of results is aimed at than is the expectation on which the British recommendations are based. Indeed, it is important to point out that the latter must not be regarded as values which cannot be exceeded with advantage. That something is to be gained by adopting better standards has, in fact, been stressed in the preceding section III $(c)$, while, in certain factories, it is now a breach of the Factory Lighting Regulations to provide less than 6 foot-candles over working areas. Moreover, this minimum is without prejudice to any additional illumination required by the nature of the work, and the provision of such higher illumination where necessary is now obligatory.

\section{Individual Differences in Light-need}

The standards of illumination derived from investigations of the kind discussed in this paper, as well as those obtained by analysis of current good practice, are values suitable for 'average' persons. But it must be borne in mind that for various reasons, individuals differ widely among themselves in the amount of light they need to do a given task comfortably and efficiently. Inherent differences in the optical and neural apparatus for seeing, acquired defects from injury or disease, and the inevitable differences due to the age of the eyes-as well as other factors-all produce a considerable spread about the average. Thus a considerable proportion of a factory population may require more, or could manage as well with less, than the code recommended illumination for average persons and the given class of work. A by no means negligible fraction may apparently see as well as ' average' people with much less light; others may require much more. It is most important to recognize this fact in dealing with the lighting of fine work and Weston (1944) has drawn attention to the fact that, for an equal performance of such work, the illuminations required by different individuals in an unselected group may range between extremes which are in a ratio of the order of 100 to 1 .

Moreover, the relative efficiency of individual workers doing the same job, i.e. their value as producers with reference to the best of them, is, in part, a function of illumination. This means that as the level of illumination is raised-while the efficiency of all the workers improves-the proportional gain is greater for the inferior than the superior workers, so that the former tend to catch up with the latter. This effect is illustrated in Fig. 11, and, of course,

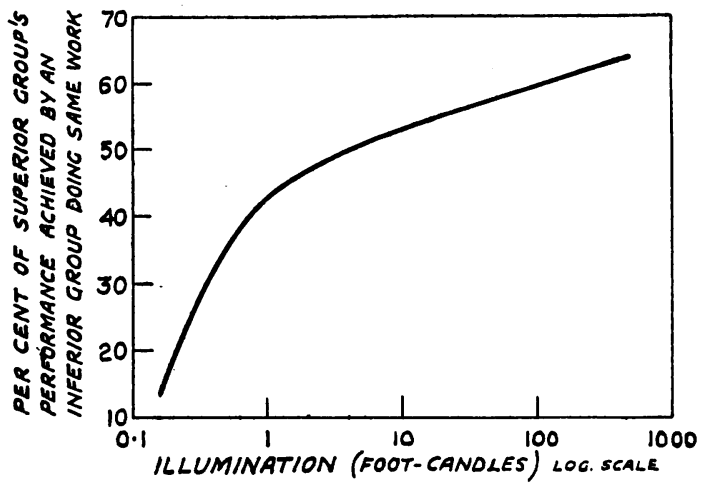

FIG. 11.-Effect of illumination on inequality of capacity among persons doing fine work.

it is clear that the maximum efficiency of a nonhomogeneous group of workers can only be secured when conditions are optimal for the worker whose light-need is greatest. In practice, it is common to provide persons doing fine work with adjustable lighting units, and it should occasion no surprise to find that persons doing similar work arrange these individually to give widely different illuminations.

\section{Maintenance}

The values of illumination required by law in factories, namely those applicable to working areas, and the minimum of half a foot-candle specified for all other interior parts over which persons employed are liable to pass, are those which must be maintained. Therefore, in planning the lighting of a factory, higher initial values must be arranged for, so as to allow for normal depreciation in service, which must occur with the accumulation of dust and dirt on windows, lamps, and fittings, and with the ageing of artificial light sources. The values recommended for the work, in lighting codes, are service values and, to maintain them, regular cleaning is essential at intervals which must be determined by local conditions.

\section{Factors Affecting the Suitability of Lighting}

In addition to the amount of light required, which has been dealt with in some detail in the preceding sections, there are other important factors upon which the suitability of lighting for work depends. In the present state of our knowledge some of these must be discussed chiefly in descriptive rather than quantitative, terms. 
(a) Distribution of Light

It should never be forgotten that the function of lighting in the factory is to brighten the general environment of the worker, and not only the objects to which his visual attention must be specially directed in performing his given task. It is the whole-man whose needs must be satisfied, for the work-man is surely nothing less than this. If we choose to call him workman when he clocks-in at the factory, let it be remembered that he does not, at the same time, clock-out any of his normal susceptibilities. He sees the factory and sees it whole-whether he wants to or not; and all the visual sensations and perceptions which arise from his environment, as well as his work, and are items in the inventory of his experience, have some influence on the general tone of feeling. Even when attending to objects of special interest we are not

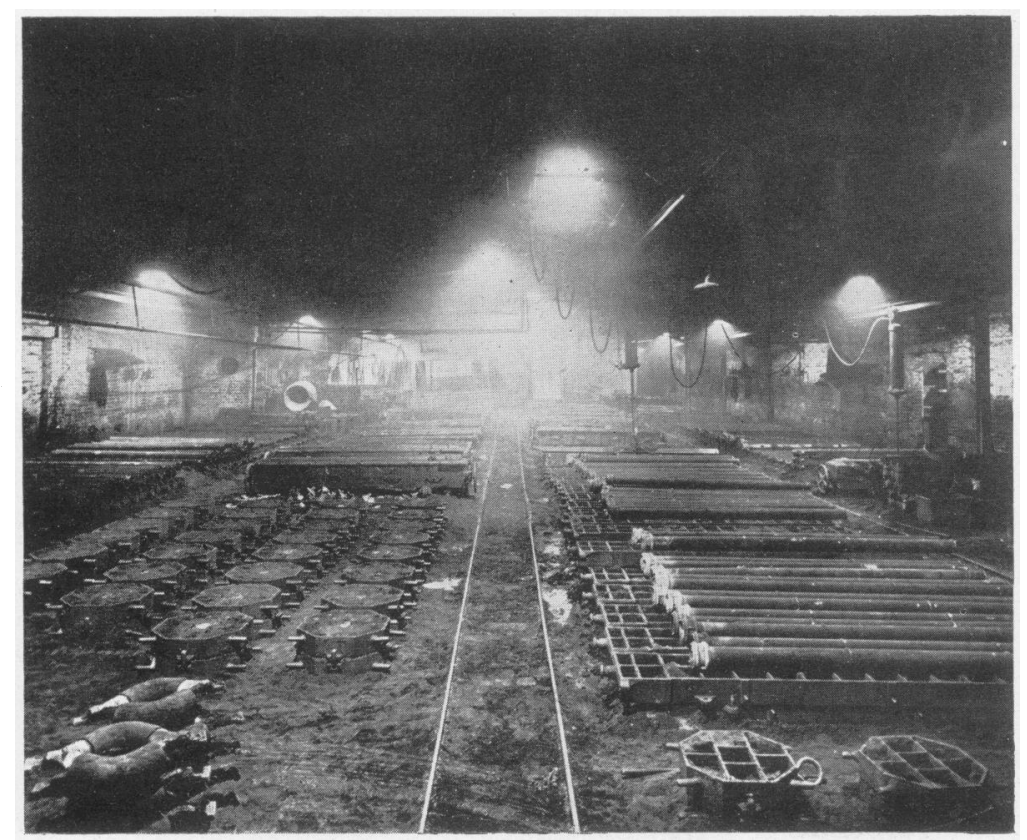

FIG. 12.-Light distribution badly planned, concentrating only on working plane.

unaffected by visual impressions received from the surrounds. They enter into our ' marginal awareness' and form part of the subconscious experience which affects our sense of our general condition. As Ward puts it, ' they tell on conscious life as sunshine or mist tells on a landscape, or the underlying writing on a palimpsest.' * Moreover, as Stout points out, "their subconscious presence is a condition which favours their emergence into distinct consciousness. . . . If my attention flags in reading my book, I may begin to notice a candle-flame. The visual sensations, which had previously been subconscious, cease to be subconscious, and become separately discerned, yielding at the same time a distinct apprehension of the candle-flame.' $\dagger$ Thus in the factory, where visual preoccupation with the work is by no means continuous, there are many opportunities for visual sensations excited by the general surrounds to break in upon distinct con-

* Ward, James, Psychological Principles, p. 94

$\dagger$ Stout, G. F., Manual of Psychology, p. 134. sciousness. The distribution of an adequate amount of light in all directions in the factory, is plainly necessary if these sensations are to promote cheerfulness. Such a distribution is usually achieved with daylight in modern factories in uncongested areas, especially factories of single-storey structure with roof windows. It is one of the reasons why daylighting is universally preferred to artificial factory lighting of the most prevalent types. While the trend of recent practice in artificial lighting has been towards the distribution of a better share of light to parts of the factory other than the working plane, it has become very evident, during the war, that artificial lighting, as it still exists in many factories, is psychologically unsatisfactory. The upper parts of workshops are frequently unduly dark, giving what has become known as the 'tunnel effect,' and making the light sources themselves too conspicuous and obtrusive. Where the latter are mounted at a relatively low height, and provided with opaque reflectors directing all the light in a downward direction, the work itself may be well lighted but a large area of the general field of vision is left almost black. Much of the rest of it may also be of low brightness, if the machines are painted in the conventional dark colours, and heavy shadows are cast on the floor. These conditions are by no means uncommon and are very depressing. Weston (1941) has described such a case, in which the factory was known to the workers as 'the dump,' and, in the words of one of themwhose breakdown seemed imminent- " the tendency among the younger ones is just to look forward to knocking-off time .... and sink into a "fed-up " attitude to the rest.' A considerable improvement in this factory was effected by installing additional lighting units, to illuminate parts of the interior above the level of the work lights.* A typical example of a light distribution planned without proper regard for the general appearance of the interior, and concentrating only on the working plane, is shown in the accompanying photograph, Fig. 12.

Recognizing the importance of a bright and cheerful appearance of the factory, the Departmental Committee on Factory Lighting (1940) recommended that, throughout the interior parts of factories where persons are regularly employed, parts of walls, partitions, ceilings, tops of rooms, inside of windows where daylight is obscured and, as far as practicable, other structural fixtures which are less than 20 feet above floor-level shall be maintained light in colour. This recommendation has not been embodied in any statutory regulation, but its implementation is most desirable, and would enable satisfactory general brightness to be achieved with the greatest economy of light.

* Illustrations of this factory appear in the pamphlet, ' Heating and Ventilation, Lighting and Seeing,' recently issued by the Industrial 
On the physiological side, an adequate brightness of the general field of view is important for the functional efficiency of the eye. Lythgoe (1932; 1936) has shown that acuteness of vision only continues to improve up to high illuminations providing the surrounding field of vision is also adequately illuminated. This appears also to be true for other visual functions which have been investigated. Both on psychological and physiological grounds it is thus a principle of good lighting that the brightness of the surrounding field of vision should not differ greatly from the brightness of the work, nor should the brightness of the general field of vision be very patchy. It is clear that, apart from the depressing effect of dark surroundings on the feelings, and on visual functions, they involve an appreciable change of adaptation every time the gaze is shifted from the work to the surroundings. If this shifting of the view occurs frequently, it is likely that, for a substantial portion of the time spent in the factory, the eye is not fully adapted to either level of brightness it encounters.

The different methods of distribution of artificial light are classified as direct, semi-direct, general, and indirect. In the direct method it is usual to employ enamelled steel reflectors which re-direct all upward light from the lamps in a downward direction. It is thus an economical method of lighting the work, and for this reason is most extensively used. But, as already pointed out, it secures good illumination below the fittings, while above them the interior is left relatively dark, since it only receives light indirectly after reflection from the floor, workbenches, and lower parts of walls. If the latter are-dark in colour, or dirty, very little light indeed may reach the upper parts of the workshop. Where such an installation is used, it is often desirable-though rarely done-to install some lighting units for the special purpose of brightening the roof and upper parts of the walls.

The semi-direct method achieves this object fairly well, either by the use of translucent, or prismatic, glass reflectors, or by steel reflectors partly open at the top, thus allowing some fraction of the direct light from the lamps to be distributed in the upper hemisphere. In the method of general distribution, enclosing fittings of diffusing glass are used, and these allow the light to be distributed in all directions. For obvious reasons they are not very suitable for use in some factories, and are actually used only in a few. Their use in offices is far more widespread. The indirect method is difficult to apply in many factory buildings and, for a given illumination on the working plane, it is the most costly method of lighting. However, it can give excellent results, in respect both of appearance of general brightness and visibility of the work. It is a suitable method of lighting rooms devoted to such operations as gauge inspection, since the resulting brightness is very uniform, and fine detail on polished metal parts, e.g. scales and verniers, is most easily seen.

\section{(b) Effects of Glare}

(i) Direct Glare.-Glare is always present when there are areas within the field of view whose brightness greatly exceeds the average brightness of the field. It is, therefore, largely a matter of brightness contrast. Thus, the filament of a bare electric lamp, which has a brightness of some thousands of candles per square inch, is a source of glare if it is visible to anyone whose eyes are adapted to the general level of brightness of the whole field illuminated by the lamp-which may be only a few footlamberts (equivalent foot-candles). It is unnecessary to instance other examples of conditions causing direct glare, since they are very familar, and are, unfortunately, very prevalent in industry.

It has been shown, e.g. by Stiles (1929), that the brightness difference threshold is raised, i.e. the contrast sensitivity of the eye is lowered, by the presence of a glare source in the field of view, and the magnitude of this effect varies inversely with the angular separation of the glare source and the line of vision. Stiles expressed the glare effect in terms of the background brightness of the field of view which, in the absence of the glare source, would correspond with the reduced contrast sensitivity. Put in another way, the effect of the presence of a visible glare source is to reduce the effectiveness of a given illumination on the work, so that, to be equally visible, the latter needs a higher standard of illumination than is necessary when glare is absent. Thus glare is wasteful, in that it discounts the value of a given standard of illumination, so that it yields disappointing results, or, alternatively, involves additional expense in providing higher illumination. It has already been pointed out in section III that the standards of illumination embodied in any lighting code must be based on the assumption that other conditions which affect the suitability of lighting will be satisfactory. They are strictly valid only when this is so, and one of the conditions assumed is the absence of glare.

Two forms of glare are generally recognized, namely, disability glare, which temporarily impairs vision, and discomfort glare, which is more or less unpleasant but does not appear to interfere with the performance of the eye. Both types of glare are still common in industry, but the second is perhaps most widespread, and is often not recognized as such, since its effects tend to be general rather than specific, and may be attributed to other causes. It seems likely, as Harbinson and Bartlett (1934) have suggested, that the discomfort associated with glare is partly a function of the task rather than of the glare stimulus directly. But this means that the more difficult is the task the more important is the avoidance of glare. So far as disability glare is concerned, the need for its avoidance should require no emphasis. Not only may it interfere directly with production, but it may be an actual source of danger to workers, since it can result in failure to see some obstacle, or other object, in consequence of which the worker suffers injury.

Unfortunately, there is at present no simple means of measuring the glaring properties of a lighting installation, such as we have for measuring the illumination it provides. In this respect then, appraisal of an installation is a matter of judgment based on experience, and of a due appreciation of the factors involved in the causation of glare. However, rules have been suggested for the avoidance or limitation of glare, and these include the restriction of the brightness of the light sources, and of their location with respect to the eye, the restriction of the volume of light reaching the eye directly from any light source, and the specification of a maximum ratio of brightness of source to brightness of surrounds. From consideration of daylight conditions, 
it has been suggested that the latter should not exceed 100 to 1 , a value which is much lower than is usually found under conditions of artificial lighting.

As mentioned in section II, the Factory Lighting Regulations attempt the control of glare by setting a limit to the permissible brightness of any part of a light source or fitting which is visible within an angle of elevation of 20 degrees from the eyes of any person, while normally employed within a distance of 100 feet from the source, unless the latter is mounted at a height of more than 16 feet above floorlevel. The specified limit of brightness is 10 candles per square inch and, like all such limits embodied in legal requirements, it does not represent the ideal condition, being only intended to protect the worker from exposure to unreasonably bad conditions. The really desirable maximum brightness of lighting units, visible as described, is probably not more than half, or better still one-quarter, of the statutory maximum. Compliance with the regulation for the control of glare, or the achievement of more comfortable conditions than this will secure, involves the use of suitably designed and installed lighting equipment. In the case of a local light, which is defined as any light so placed as to illuminate part, or all, of the area of work of a single operative or small group of operatives working near each other, the light source must now be completely screened from the eyes of every person employed at a normal working place.

It is, of course, quite possible to experience glare in daylight, if work is done facing a window. A small window is usually more troublesome in this respect than a large one, because its brightness may greatly exceed that of the surrounding wall surface which is its background and which may receive no direct daylight.

(ii) Glare by Reflection.-Glare is very frequently caused by the reflection of bright light sources in polished surfaces, which may be those of the work material, or of parts of machines and metal fixtures, or walls finished with high gloss paint. It is often very annoying and troublesome, and increases the difficulty of the work and the fatigue of the worker.

Wyatt and Langdon (1932) have observed the effects of glare, due to reflection, on the performance of women examining cartridge cases. The workers complained that the electric light produced a disturbing dazzle from the brass caps of the cases, which made the task of inspection more difficult and fatiguing than they found it in diffuse daylight. Fig. 13 shows the effect of this dazzle on the rate at which two of the inspectors were able to do the work.

The reduced rate under artificial light means a fall in output of about 6 per cent., and it is very likely that a similar effect occurs in many factories where the same method of artificial lighting by concentrated high brightness sources is used for work with specular material.

It has been mentioned already that indirect lighting is very suitable for illuminating work of this kind, since the effective light sources are of large area and low brightness, so that their reflections in polished material are not dazzling. But other methods are also satisfactory, such as lighting by means of luminous panels or other secondary light sources of low brightness, or by means of fluorescent tubular lamps. Some such method should, in fact, be used in factories to which the current statutory lighting regulations apply, since it is required that

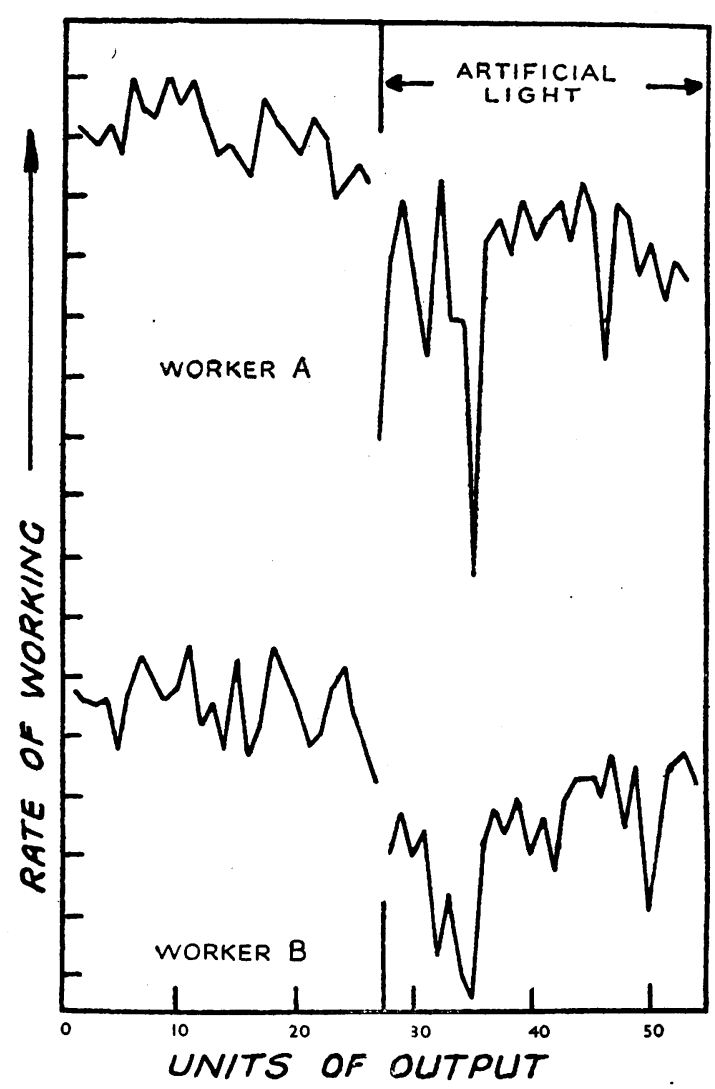

Fig. 13.-Reduction of rate of working, due to dazzle from the work caused by unsuitable artificial lighting.

'so far as reasonably practicable, arrangements shall be made, by suitable screening or placing or other effective method, to prevent discomfort or injury by the reflection of light from smooth or polished surfaces into the eyes of the worker.'

\section{(c) Diffusion and Shadow}

The presence of dense shadows in factories is generally unpleasant and sometimes very inconvenient, or even dangerous. To avoid them a considerable degree of diffusion in lighting is necessary, such as is usual in daylight. With artificial lighting the greatest diffusion is obtained by the indirect method, by which all the light from the lamps is thrown on to the ceiling and then reflected in all directions throughout the interior. Such a high degree of diffusion is not necessary for most industrial processes, and is definitely undesirable for some in which the presence of detail in the work is revealed mainly by the formation of shadows. The texture of self-coloured materials, such as textile fabrics, and the detail of many other threedimensional objects is seen partly by means of shadows, but even in these cases the degree of diffusion which is usual in the daylighted factory appears to be generally satisfactory. The general, semidirect and direct methods of artificial lighting provide - in the order given-lesser degrees of diffusion.

In the case of type-setting by hand, an operation where shadows play some part in rendering the detail of the type visible, Weston and Taylor (1928) 
found the direct method of lighting gave the best results, though there was little to choose between this and semi-indirect or even indirect lighting, and none of these systems of artificial lighting gave better results than natural daylighting. Weston (1938) studied the effects of different methods of lighting for weaving. One of the installations tried provided strongly directional light coming from one side of the looms, so as to accentuate the contrast between the warp threads by giving them a high brightness on one side while the other was shadowed. The effect on the performance of the weavers was not significantly better than that of a conventional direct system of lighting giving about the same illumination on the working plane. This result is not in agreement with that reported by Goldstern and Putnoky (1931).

Lighting from a particular direction is, however, certainly valuable in some cases for the purpose of casting shadows which can facilitate the perception of detail. It is also often necessary in order to get adequate illumination on particular objects, but local light sources can generally best be used for this purpose. Owing to the structural characteristics of machinery, the presence of overhead gear, materials racks and so on, the avoidance of disturbing shadows over parts of the working area is not always easy, and calls for skill and experience in planning the lighting installation. It is now obligatory however that 'adequate measures shall be taken, so far as reasonably practicable, to prevent the formation of shadows which cause eyestrain or risk of accident to any person employed.'

\section{(d) 'Colour' of Light}

We naturally take the apparent colour of objects illuminated by daylight as their normal and expected colour quality. But, as is well known, the light emitted by most artificial sources now in common use differs in composition from natural light, though the latter is not itself constant in this respect. This difference affects the apparent colour of objects as seen in artificial light, and it is a familiar fact that accurate matching of certain colours cannot be done in ordinary artificial light. Unconsciously, however, we make allowances for the effect of lights which do not greatly differ in 'colour' from daylight, so that we can accept the appearance of many familiar objects illuminated by them as being natural in colour. Accordingly, for all ordinary purposes it is found that lighting by gas lamps or electric filament lamps is satisfactory so far as its rendering of colours is concerned. Discharge lamps, in which the light is produced by the electrical excitation of gases or vapours, emit light only in certain regions of the spectrum. Although, on this account, the apparent colour of familiar objects illuminated by them is considerably changed and made obviously unnatural, experience seems to show that the visibility of some classes of work, e.g. in engineering machine shops and foundries, is not adversely affected. It has, in fact, been claimed that mercury and sodium discharge lamps improve the visibility of work of this kind, but there appears to be no adequate evidence for this. Many workers seem readily to adapt themselves to the altered-and certainly, at first, the unpleasantappearances due to these types of light source, but the author has found none who actually prefers this to more natural lighting.
To improve the colour characteristics of highpressure mercury discharge lamps they have been modified by enclosure in an outer bulb having, internally, a coating of fluorescent powder. This transforms some of the invisible ultra-violet radiation emitted by the lamp into visible light, which makes good some of the deficiency in red which is characteristic of the bare lamp emission. Lamps of this kind are now extensively used in factories. They are efficient sources of light, but are only a little better than the plain mercury discharge lamps, so far as colour rendering is concerned. Another method of securing better colour characteristics is to use both plain mercury discharge lamps and tungsten filament lamps together. Either two lamps-one of each kind - can be used in each fitting or reflector, or the two light sources are available combined in a single bulb.

Much more natural colour rendering is now obtainable with the use of what is known as the white, or colour 'A,' 80-watt fluorescent lamp. During the war many of these lamps have been installed in factories, particularly in those from which daylight is permanently excluded. They are lowpressure mercury discharge lamps in tubular form, internally coated with a mixture of fluorescent powders, by means of which the ultra-violet light from the discharge is very effectively converted into visible light. In composition this closely resembles the natural light available on a summer day. The characteristics and applications of these lamps are fully described by Atkinson (1944).

There can be no doubt that the introduction of such lamps has made possible a great advance in the artificial lighting of factories, whereby so close an approach to natural conditions can be achieved that the common prejudice against working for long periods by artificial light can usually be overcome. Not only is the colour of the light very satisfactory, but the brightness of the lamps is relatively low, so that glare is less likely to be experienced. The tubular form of the lamps is also an advantage for many applications.

In a considerable number of factories, even in peace-time when no part of the window area is permanently and intentionally obscured, daylight does not penetrate to a substantial part of the working area in sufficient quantity for the work. It has, therefore, to be supplemented all day by artificial light, but this is unnoticeable when it is done by fluorescent tube lighting.*

The accompanying photograph, Fig. 14, while it cannot show the daylight colour appearance of the factory given by fluorescent lighting, shows that the fluorescent tube is well suited to an arrangement of light sources which is in itself less obviously artificial than conventional arrangements of small conconcentrated light sources. The tubes are mounted end to end in continuous troughing and this, in conjunction with their colour and moderate brightness, tends to the impression that the factory is lighted by narrow overhead windows.

Some approximation to the colour quality of daylight can be obtained by using various corrective devices, e.g. colour filters, in conjunction with

* At present the installation and use of this, and all forms of discharge, lighting is controlled under S. R. \& O., 1943, No. 1201. The Minister of Works is unlikely to grant the necessary licence for the Minister of Works is unlikely to grant the necessary licence for the
use of fluorescent lighting except in cases covered by a War Emergency Lighting prepared by the Institution of Electrical Engineers. 


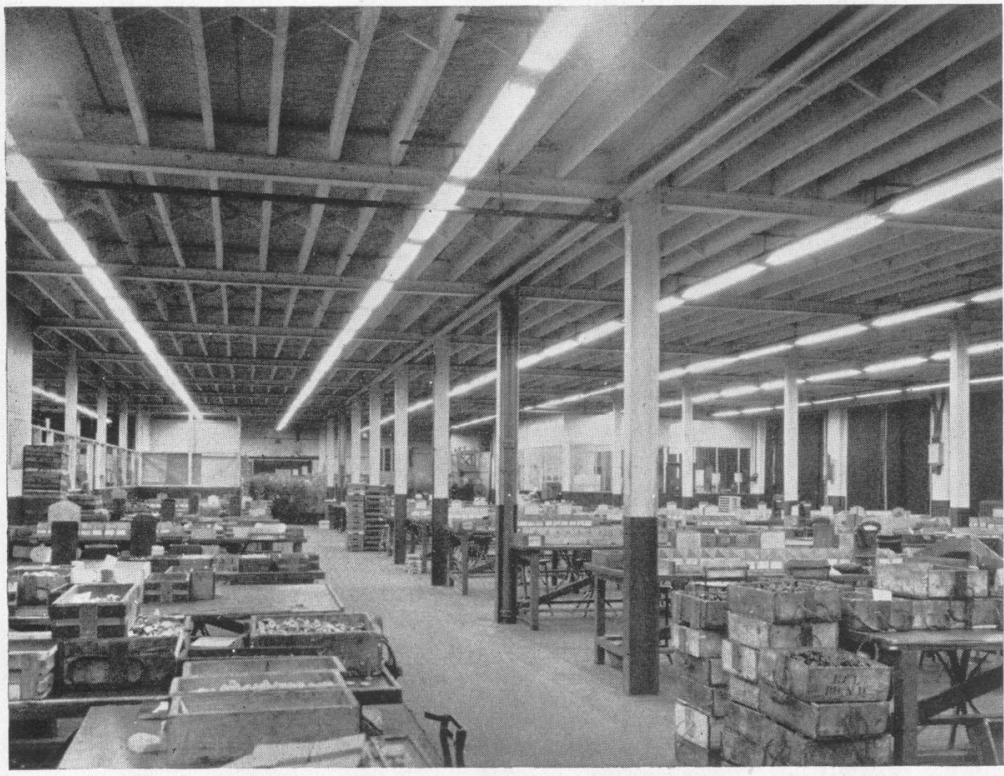

FIG. 14.-Fluorescent tubular lighting.

50-cycle supply appear to be of rare occurrence in the factory.

In the case of electric discharge lamps, the luminous arc is actually extinguished 100 times a second when the lamps are operating on a 50-cycle supply. Consequently, the periodic variation of illumination is much greater than with filament lamps, though the fluctuations are too rapid for flicker to be apparent when looking at the lamp, or at stationary objects illuminated by it. An effect akin to that of flicker may, however, occur when moving objects illuminated by discharge lamps are observed. Such an object, being illuminated intermittently, may appear to move in a jerky manner, or if the moving object is a rotating one, such as a spoked wheel, its apparent speed may be faster or slower than its true speed, or it may appear to be at rest.

ordinary tungsten filament lamps. As some of the light radiated by the lamps is subtracted by these devices and converted into heat, it is relatively costly to obtain so-called artificial daylight by their use. For very accurate colour matching, however, special lamps are required which provide light of a standardized colour quality.

It must be added that there is no reliable evidence that ordinary artificial lighting, e.g. gas or tungsten lighting, is physiologically undesirable on account of its colour quality, but for most people there is little doubt of the psychological value of natural or simulated natural lighting.

\section{(e) Stroboscopic Effects of Discharge Lighting}

In their fourth report (1938), the Departmental Committee on Lighting in Factories referred to the fact that cases still occur of fatigue and danger arising from the use of flickering or inconstant light sources in factories. They, therefore, recommended that the use of such sources should be prohibited, but this recommendation was not intended to apply generally to electric lamps, either of the filament or discharge type, operating on an alternating current supply having not less than the usual frequency of 50 cycles per second.

There is no perceptible flicker in the case of tungsten filament lamps operating on the usual 50-cycle supply, since the thermal inertia of the filament prevents the light output from fluctuating noticeably. In any case, as there are two fluctuations per cycle, the frequency is well above the critical frequency at which flicker disappears for the light-adapted eye. With a moving object it is possible, however, to observe a stroboscopic effect, and use is made of this in a simple device for checking the speed of gramophone turntables. This consists of a disc, having the necessary number of radial lines, or spokes, which, when observed by tungsten lighting on the rotating turntable, appears to be stationary if the speed of rotation is correct. Stroboscopic effects due to tungsten lighting from a

These effects may be disconcerting, uncomfortable, and, in some circumstances, dangerous. There are, however, several methods by which they can be minimised so as to be generally unobjectionable. One method consists in mixing tungsten lamps with discharge lamps in the intallation, but this is not the most suitable method if discharge lamps of the fluorescent tubular type are used. The other methods are concerned with the location and circuit arrangement of the lamps. Their object is to ensure that any workplace receives its illumination from two or three lamps which are arranged to be out of phase, so that when the illumination from one lamp is falling that from the adjacent lamp is rising. In this way the variation of illumination on the work is reduced. With fluorescent tubular lamps there is some after-glow from the powder during the periods of extinction of the arc, and this also tends to render stroboscopic affects less noticeable. But, when single lamps of this type are used, they may be found unsuitable for the illumination of some industrial operations, or be disliked by some persons.

\section{Colour of Decorations and Machines}

Some reference has already been made to the importance of light coloured surfaces within the factory if the interior is to present a bright and cheerful appearance. Given identical factory buildings having similar fenestration and installations for artificial lighting, it is evident that the visual impressions their occupants receive will depend on the colours of the structural surfaces and fixtures which make up the visible environment. In spite of equal lighting, one factory may look grim and forbidding -as the 'dark Satanic mills' of which Blake wrotewhile another of the same kind may look bright and inviting. The difference is a matter of colours and their brightness factors, or luminosity values. Some industrial processes are dirty, and it is, presumably, for this reason that dark-coloured decorations and dark-coloured machines are often found in factories where they are carried on. But dirty 
work is a better reason for the choice of light than of dark colours. Even a dirty light colour is brighter than a dirty dark colour, and dark colours do nothing to encourage cleanliness.

Agricultural machines, which are used out of doors, in full daylight, are customarily painted in bright and gay colours, yet the machines of many indoor industries are commonly finished in black or other dark colours, though they receive far less light. The sum of human cheerfulness would be increased if the traditional practice in these two cases were interchanged. But there seems no good reason why the practice of the oldest industry should not become that of the others. It is true that where the importance of cleanliness is most obvious, e.g. in food factories, including dairies, light coloured decorations and machines are often found but, in factories generally, there is much room for improvement in this respect.

But the achievement of agreeable brightness is not, of course, the only consideration which should influence the choice of colours in the factory. Colour contrast is a most valuable aid to vision and, in the absence of brightness contrast, is the only means by which visual discrimination is possible'all that is properly perceived by the visive faculty amounts to no more than colours with their variations, and different proportions of light and shade.' * With the aesthetic value of colour we are not primarily concerned in this paper, but it is neither wise nor necessary to disregard it in the pursuit of good visibility.

Some interesting colour experiments have recently been made in engineering shops, both here and in America. In one large machine shop in the Home Counties all the machines have been painted pale cream, certain small parts, which must be readily distinguishable, being treated in other colours which are harmonious but in good contrast, e.g. the electrical control boxes are painted orange. Materials racks are painted a pleasing green. The walls and stanchions, above a three-foot dado, and also the roof, are also painted cream, while the dado itself is green. The conditions for seeing are excellent, and on entering the shop from a neighbouring untreated one having the usual mass of black and battleship-grey machines, one is instantly aware of an almost dramatic favourable change of feeling. The light paint on the machines has proved as serviceable as the traditional dark colours, and the operatives take pride in keeping it clean. They have facetiously called the shop 'the dairy'-an appellation as significant of its value in promoting health as is the contrary significance of "the dump " mentioned earlier in this paper.

Elsewhere, similar transformations have been effected and welcomed. Nelson (1943) has recently described a colour scheme planned by him and applied to part of a large Midland engineering works. An idea-though necessarily an inadequate oneof its agreeable effect is given by the accompanying photograph (Fig. 15) for which the present author is indebted to Dr. Nelson.

In America, Denning and Brainerd (1942) have experinented with the colouring of machines with the object of facilitating visual discrimination by means of colour contrast. The expression ' three dimensional seeing,' which has been used in con-

* Berkeley, A New Theory of Vision, CLVI.

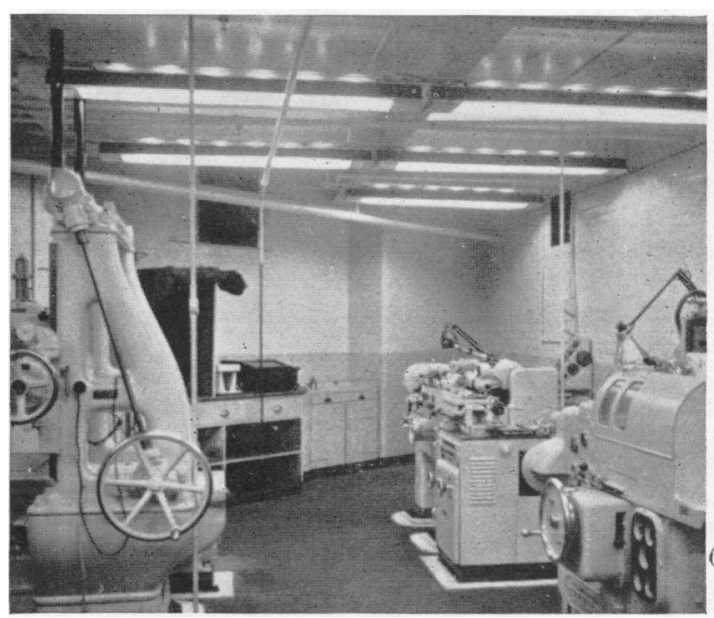

무

를

这

$\stackrel{\vec{\prime}}{\circ}$

7ृ

क

$\vec{\circ}$

$\vec{\omega}$

FIG. 15.

nection with their work, arises from the suggestion that discrimination is assisted by a 'stereoscopic' effect given when suitable contrasting colours are used and appropriately disposed. For example, an object in colour contrast with its background may also appear to 'stand out' from it if the colours are suitably chosen. Goethe observed some such effect, and explained it on the basis of the spatial ideas associated with colours as observed in nature' as we see the high heavens, the distant mountains blue, a blue surface appears to recede before us. . . . On the other hand, the complementary colour, yellow, and colours of longer wavelength tend to 'advance.' The chromatic aberration of the eye has also been invoked to account for this effect, though whether it really appears, in the absence of other visual presentations suggesting perspective, may be doubted. Inasmuch, however, as certain colours excite preferential attention they may, in this sense, be said to stand out.

As to their effects upon feeling, Goethe classified colours as positive and negative-the former including red, orange, and yellow, and the latter green, blue, and violet. The positive, or active, colours are stimulating; the negative, or passive, are restful, subduing or depressing. But this aspect of colour cannot be discussed at length here, nor can the subject of harmony of colour, for which, as Helmholtz pointed out, rules cannot be stated with the same certainty and precision as for the consonance of tones.

In colouring the factory, however, strongly saturated colours should not be used for extensive surfaces. Pastel shades not only have the advantage of a high brightness factor, but are too weak in hue either to fatigue the colour sense or violently offend individual taste. It is not necessary to paint all the machines in a shop exactly alike. Uniformity in this may be preferred, as giving an orderly appearance, but variety, without motley, can be achieved by varying the shade but not the colour quality used for different machines, or by using different unsaturated colours for banks of different machines. As the apparent colour of paints is affected by the nature of the light in which they are seen, the kind of artificial lighting in the factory must be taken into 
account, especially in selecting what is to be the prevailing colour. For example, light which is deficient in red, e.g. the uncorrected light of mercury discharge lamps, gives a yellow surface rather a sickly hue. Sodium lighting distorts most colours, e.g. red appears as chocolate. Where tubular fluorescent lamps are used colour rendering is almost natural, but slightly ' warmer' tints than the daylight choice may be used. The room illustrated in Fig. 15 has fluorescent lighting, and the colour scheme is "pale cream' for the walls with ' eau de nil' dado, and 'Portland stone' for the machines.* The skirting round the walls and machines is dark green and the ceiling is white. Thus, the luminosity value of the light reflected from the surfaces which occupy most of the field of view is of a high order. Matt or ' eggshell' rather than high gloss finishes should be used, as far as possible, to avoid glare by reflection.

In the case of bench work, seeing conditions can often be improved by providing a background contrasting in colour with the work material. The latter itself should be selected for easy seeing whenever there is some freedom of choice.

\section{Lighting for Safety and Hygiene}

Little has been said in preceding sections concerning lighting in relation to the prevention of factory accidents, but the standards of lighting required by the statutory regulations now in force have specific reference to the safety of workers.

In the strict sense an accident is an event due to pure chance, but many so-called accidents are undoubtedly events whose occurrence could be averted if our senses served us as well as they might. On this account, it can be said that the better the conditions of factory lighting - up to the point of maximum efficiency of vision - the better the insurance against accidents. It certainly cannot be assumed that the conditions of lighting which cheer and enliven us, and are consistent with a high standard of industrial efficiency, are better than those desirable for safety at work.

It is known that daylight, even in the absence of direct sunlight, is bactericidal, but this effect has been regarded as due to its ultra-violet components. Only a little of the near ultra-violet radiation penetrates through ordinary window glass, and probably all of this is filtered out by two thicknesses of glass. In spite of this, Garrod (1944) has recently brought forward evidence suggesting that diffuse daylight, i.e. visible daylight, has some bactericidal action and, on this account, is to be regarded as a hygienic safeguard. Garrod's observations were made in hospital wards, and showed that the effect depends on the strength of the light, since it varied with distance from the windows. Possibly the relative energy of parts of the spectrum also varied with distance, owing to selective absorption in the atmosphere. Nevertheless, as the effect appears

* These are standard colours, specified in B.S. 381, 1930, issıed by equation is given for each scheduled colour. to be due to visible light, it must, if confirmed by further observations, strengthen the case for good artificial as well as natural lighting in factories. For the purpose merely of revealing the presence of dirt and dust-which harbour bacteria-and of encouraging cleaning, the need for good factory lighting is too obvious to require emphasis here.

\section{Conclusion}

The design of good factory lighting, whether natural or artificial, is the business of the illuminating engineer and the architect. But, while it is for them to understand and exercise the practical art of lighting-so as to fulfil the requirements which physiological and psychological considerations show to be necessary for a proper standard of well-being -it is not only for them, but clearly also for the industrial medical officer, to know what those requirements are. It is only with the latter that this paper attempts to deal, even in outline. It is hoped, however, that it may assist those whose special function it is to promote in people at work healthy minds in healthy bodies, to assess conditions of lighting as they find them in the factory, and to point out in what respects improvement may be required.

\section{REFERENCES}

Adams, S. (1935). Joint Rep. Industr. Hlth. Res. Bd. and Illum. Res. Comm., D. S. \& I. R., Lond.

Atkinson, A. D.S. (1944). Fluorescent Lighting. London: G. Newnes, Ltd.

Beuttell, A. W. (1934). Illum. Engr., 27.

Denning, M., and Brainerd, A. A. (1942). Product. Engineering, 37.

Departmental Committee on Lighting in Factories (1938; 1940). 4th and 5th Reports, Lond.

Elton, P. M. (1920). Indust. Fat. Res. Board Rep. No. 9.

Garrod, L. P. (1944). Brit. med. J., 1, 245.

Goldstern, N., and Putnoky, F. (1931). Licht und Lampe, Nos. 1 and 2, Berlin.

Harbinson, M. R., and Bartlett, F. C. (1934). Brit. J. Psychol., 24, Part 3.

I.E.S. Code: Recommended Values of Illumination. (1942.) 4th Edition. Illum. Eng. Soc., Lond.

Lythgoe, R. J. (1932). Spec. Rep. Ser., Med. Res. Coun., Lond., No. 173.

(1936). Trans. Illum. Eng. Soc., 1, No. 1.

Nelson, J. H. (1943). Light and Lighting, 36, No. 12.

Stiles, W. S. (1929). D. S. \& I. R., Illum. Res. Tech. Paper No. 8.

Weston, H. C. (1922). Industr. Fat. Res. Bd Rep. No. 20.

—, and Taylor, A. K. (1926). Joint Rep., Ind. Fat. Res. Bd. and Illum. Res. Comm., D. S. \& I. R., Lond.

-, (1928). Joint Rep. Ind. Fat. Res. Board and Illum. Res. Comm., D. S. \& I. R., Lond.

(1935). Joint Rep. Industr. Hlth. Res. Bd. and Illum. Res. Comm., D. S. \& I. R., Lond.

(1938). Industr. Hith. Res. Bd. Rep. No. 81.

(1941). Trans. Illum. Eng. Soc., 6, No. 10.

(1943). Ibid,. 8, No. 2.

(1944). Trans. Ophth. Soc., 63.

Wyatt, S. (1923). Industr. Fat. Res. Bd. Rep. No. 23.

-, and Langdon, J. N. (1932). Ind. Hlth. Res. Bd. Rep. No. 63 . 